\title{
Serum level of some micronutrients in children infected with Helicobacter pylori
}

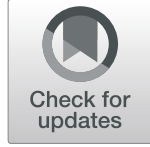

\author{
Ashraf Mohamed Elsaghier ${ }^{1 *}$ (D), Fardous Hanem Abdel Aal ${ }^{1}$, Nagla Hassan Abu Faddan', Hekma Saad Farghaly ${ }^{1}$, \\ Mona Abd-Elhamid Hassan ${ }^{2}$ and Mahmoud Farouk Sherif ${ }^{3}$
}

\begin{abstract}
Background: Helicobacter pylori (H. pylori) proved to be highly prevalent all over the world. H. pylori may modify the absorption of many nutrients. Studies have suggested that, beyond iron, $\mathrm{H}$. pylori infection may affect the homeostasis of other micronutrients such as vitamins and trace elements. Our study's aim was to assess the effect of $\mathrm{H}$. pylori infection on some blood micronutrient level including zinc, selenium, vitamin $C$, and vitamin $B_{12}$ in children with chronic or recurrent unexplained dyspeptic symptoms and/or non-variceal hematemesis.

Results: A cross-sectional case-control study was carried out in 32 children (4-18years) with chronic or recurrent unexplained dyspeptic symptoms and/or non-variceal hematemesis. Patients were divided according to the results histopathology and rapid urease test into two groups, H. pylori-positive patients (18 patients) and H. pylori-negative patients (14 patients). Another control group of 18 children was included. Serum levels of zinc, selenium, vitamin C, and vitamin $B_{12}$ were measured in all children. Prevalence of $\mathrm{H}$. pylori infection was $56.2 \%$. The mean serum zinc levels were significantly lower in $\mathrm{H}$. pylori-positive cases than in control group $(84.2 \pm 13.85$ versus $94.6 \pm 6.52$ with $P=0.009)$ and lower than in $\mathrm{H}$. pylori-negative cases but not statistically significant $(84.2 \pm 13.85$ versus $92.2 \pm 8.53$ with $P=0.054)$. The mean serum vitamin $\mathrm{C}$ levels were significantly lower in $\mathrm{H}$. pylori-positive cases than in negative cases and control group ( $220.7 \pm 46.16$ versus $305.1 \pm 28.83$ and $313.1 \pm 31.43$ with $P<0.0001)$. The mean serum vitamin $\mathrm{B}_{12}$ levels were significantly lower in $\mathrm{H}$. pylori-positive cases than in negative cases and control group (167.8 \pm 76.98 versus $290.1 \pm 69.92$ and $326.1 \pm 38.67$ with $P<0.0001)$. The mean serum selenium level was slightly higher in H. pylori-positive patients than in $\mathrm{H}$. pylori-negative patients and control group but not statistically significant (118.2 \pm 11.13 versus $112.1 \pm 8.69$ and $113.1 \pm 13.76$ with $P=0.096,0.243$ respectively).
\end{abstract}

Conclusion: Helicobacter pylori infection in children has a significant negative effect on the serum levels of zinc, vitamin $\mathrm{C}$, and vitamin $\mathrm{B}_{12}$.

Keywords: Helicobacter pylori, Zinc, Selenium, Vitamin C, Vitamin $B_{12}$

\section{Background}

$\mathrm{H}$. pylori is a spiral-shaped gram-negative bacterium that colonizes the stomach, and it was first discovered in 1979 by the pathologist Warren, who observed these bacteria in an inflamed gastric epithelium, and subsequently in peptic ulcer-associated gastritis. In 1981, Marshall started his research and cultivated the bacteria [1]. Since then, H. pylori proved to be highly prevalent all over the world, where it infects the gastric mucosa of about half of the world's population [2, 3]. According to

\footnotetext{
* Correspondence: ashraf.elsaghier@gmail.com

'Department of Pediatrics, Faculty of Medicine, Assiut University, Assiut

71515, Egypt

Full list of author information is available at the end of the article
}

the World Organization of Gastroenterology, the prevalence of $\mathrm{H}$. pylori in Egyptian children aged 3 years is $50 \%$ [3].

$\mathrm{H}$. pylori have been recognized as the major etiologic factor of gastritis and peptic ulcer disease in adults and children. This infection is frequently acquired during childhood and lasts into adult life, which has been linked to the development of gastric cancer [4].

Because this infection particularly develops in the stomach, it naturally affects stomach functions. Although there is no direct absorption of nutrients in the stomach, it plays a very important role, such as acid secretion, for facilitated absorption of nutrients in the small intestine. $H$. pylori also impair the normal 
secretion of hydrochloric acid, provoking achlorhydria in infected patients [5]. Additionally, bacteria may metabolize some nutrients that are important for its continued survival and may cause deficiencies in this manner. As a result of its interference, $\mathrm{H}$. pylori may modify the absorption of many nutrients and then compromise the nutritional status of infected patients, resulting in diverse clinical manifestations [6].

The association of $\mathrm{H}$. pylori with unexplained irondeficiency anemia has been conclusively proved in the pediatric population, where several studies among infected patients showed that eradication therapy increased hemoglobin levels even without iron supplementation [7].

Trace minerals and vitamins are essential for life. They act as essential cofactors of enzymes and as organizers of the molecular structures of the cell. Deficiencies of micronutrients influence immune homeostasis and thus affect infection-related morbidity and mortality [6]. Studies have suggested that, beyond iron, $\mathrm{H}$. pylori infection may affect the homeostasis of other micronutrients such as vitamins and trace elements including vitamin $\mathrm{B}_{12}$, folic acid, vitamin C, a-tocopherol, and $B$-carotene [4].

Vitamin $B_{12}$ is an essential component for both neuronal integrity and hematopoiesis. It has important functions in DNA replication, in the synthesis of red blood cells, and in maintaining the myelin sheath that surrounds nerve cells [8]. Clinical manifestations of vitamin $B_{12}$ deficiency include pallor, glossitis, knuckle pigmentation, peripheral neuropathy, demyelination of the dorsal column, pyramidal tracts in the spinal cord and rarely optic atrophy and cerebral symptoms [9].

Vitamin $C$ is one of the essential micronutrients for human health. Two major functions of vitamin $C$ are as antioxidants and cofactors. As a cofactor, ascorbic acid donates electrons for at least 15 mammalian enzymes, including hydroxylase and monooxygenase involved in the synthesis of carnitine, collagen, and neurotransmitters. As an antioxidant, vitamin $\mathrm{C}$ protects the body from various deleterious effects of free radicals and reactive oxygen species (ROS) that are produced during normal metabolic processes, via active immune cells, as well as by exposure to toxins and contaminants $[10,11]$. Low levels of vitamin $\mathrm{C}$ have been associated with many conditions, including scurvy, bleeding tendency, delayed wound healing, anemia, some cancers, infections, etc. [12, 13, 11].

Selenium is an essential micronutrient that is required by most organ systems in the body [14]. The bestknown function of selenium is its role as a cofactor of glutathione peroxidase, which protects membranes from oxidative damage. Selenium also plays a role in electron transfer functions and may affect enzymes that metabolize drugs. Its deficiency leaves most tissues vulnerable to peroxidative damage [15].
Zinc is an essential mineral found in almost every cell. It stimulates the activity of approximately 100 enzymes that promote biochemical reactions in the body. Zinc supports a healthy immune system and is needed for wound healing and DNA synthesis. It also supports normal growth and development during pregnancy, childhood, and adolescence. Zinc deficiency most often occurs when zinc intake is inadequate or poorly absorbed, when there are increased losses of zinc from the body, or when the body's requirement for zinc increases. Deficiency in this micronutrient restricts childhood growth and decreases resistance to infections, which contribute significantly to morbidity and mortality in young children [16].

In the developing countries, the addition of micronutrient deficiencies facilitated by $\mathrm{H}$. pylori infection to already present macronutrient problem is a great clinical and public health problem. This important public health problem could be resolved by the supplementation of the micronutrients and eradication of infection [15].

\section{Methods}

\section{Study design and study population}

The present study is a cross-sectional case-control study conducted during a period of 1 year from January to December 2016 and included children and adolescents admitted to the Gastroenterology and Endoscopy Unit complaining of chronic or recurrent unexplained dyspeptic symptoms and/or non-variceal hematemesis. Another control group of apparently healthy children with comparable age and sex was included.

\section{Inclusion criteria}

1. Children and adolescents between 4 and 18 years having chronic or recurrent unexplained dyspeptic symptoms (postprandial fullness, early satiety, epigastric pain, and epigastric burning) $[17,18]$ and/or non-variceal hematemesis.

2. The dyspeptic symptoms should be severe enough to interfere with the usual activities and occur at least 3 days per week over the last 3 months with an onset of at least 6 months in advance $[17,18]$.

\section{Exclusion criteria}

1. Patients who received anti-secretory drugs and/or antibiotics in the previous 4 weeks before endoscopy.

2. Patients receiving multivitamins and mineral treatment during the previous 2 months.

3. Patients having cachexia, malnutrition, or a history of an eating disorder or those with any diet restrictions and vegetarian diet. 
4. Patients with metabolic disorders such as diabetes mellitus, chronic liver disease, uremia, celiac disease, inflammatory bowel disease, or any other systemic illnesses.

\section{Clinical evaluation}

All participants were subjected to thorough medical history which included personal history; presenting symptom/s and its duration, evaluation of risk factors which included father's and mother's education, over-crowding, sanitary conditions, and sharing a bed; dietetic history; if there is excess intake of fats, spicy food, caffeine, or tea; history of extra gastrointestinal illness related to $\mathrm{H}$. pylori infection; medication history; and family history of gastrointestinal problems.

Clinical examination included assessment of vital signs, anthropometric measurements, general examination, and complete systemic examination.

\section{Laboratory evaluation}

Laboratory investigations included:

a. Complete blood picture for all patients and controls. Complete blood count using Celitac ES (NIHON KOHDEN, Japan) for leucocytic count, hemoglobin percent $(\mathrm{Hb} \%)$, and platelets count. Anemia will be diagnosed when $\mathrm{Hb} \%$ is below cut-off value for age and sex and will be graded into mild, moderate, and severe according to WHO [19].

b. Coagulation profile using Sysmex CA-600 Series: prothrombin time (PT), activated partial thromboplastin time (aPTT), and international normalized ratio (INR) done for all patients and controls.

c. Blood grouping for all patients using indirect hemagglutination test.

d. Micronutrient assay:

Serum micronutrient level including zinc and selenium were measured using colorimetric method, and ascorbic acid (vitamin $C$ ) and vitamin $B_{12}$ were measured using ELISA kit for all patients and controls.

Sample collection:

Fasting morning $5 \mathrm{ml}$ of venous blood sample from each participant was collected. Serum coagulation at room temperature for $10-20 \mathrm{~min}$, then centrifuged at speed of 2000-3000 rpm for $20 \mathrm{~min}$, then supernatant removed in an Eppendorf tubes and stored at $-70{ }^{\circ} \mathrm{C}$ till assay. Each sample was stored in different aliquots so that each sample is thawed for every single assay.

Vitamin $B_{12}$ assay: Human vitamin $B_{12}$ ELISA kit (Glory Science Co., Ltd, Add: 2400 Veterans Blvd. Suite 16 - 101, Del Rio, TX 78840, USA, CATALOG \#:11341) was used for the quantitative determination of Human vitamin $\mathrm{B}_{12}$ concentrations. The detection range of the kit is $28 \mathrm{ng} / \mathrm{L}-800 \mathrm{ng} / \mathrm{L}$.

Vitamin C (ascorbic acid) assay: Human vitamin $C$ ELISA kit (Glory Science Co., Ltd, Add: 2400 Veterans Blvd. Suite 16 - 101, Del Rio, TX 78840, USA, CATALOG \#:90081) was used for the quantitative determination of Human vitamin $\mathrm{C}$ concentrations. Detection range of the kit is $100 \mathrm{ng} / \mathrm{L}-2000 \mathrm{ng} / \mathrm{L}$

Zinc assay: colorimetric test with 5-Brom-PAPS (manufactured by Egyptian Company for Biotechnology, www.spectrum-diagnostics.com, Authorised Representative: MDSS GmbH Schiffgraben 41, 30175 Hannover, Germany, REF: 330 002). Expected values in children: 63.8-110 mg/dl (9.8-16.8 mmol/l).

Selenium assay: plasma selenium assay was done using a commercially available colorimetric assay kit, ABC Diagnostic Egypt). Reference value of the kit: children older than 1 year $70-150 \mathrm{ng} / \mathrm{ml}$.

\section{Esophagogastroduodenoscopy}

Upper gastrointestinal (GI) endoscopy was done for all patients and gastric mucosal biopsies were taken:

a. Antral biopsy for rapid urease test (Kimberly-Clark, CLO test, REF: 60480, LOT: AW529300A, USA).

The test was considered positive when the color turned from yellow into pink or violet within 60 min.

b. Antral and corpus biopsies for histopathological assessment and for confirmation of the presence of H. pylori bacilli.

Biopsies were immediately fixed in $10 \%$ formalin solution and processed by automated tissue processing till paraffin embedding and then serially cut into 5 - $\mu \mathrm{m}$ thick sections into two slides.

One slide was stained with hematoxylin and eosin for microscopic evaluation to detect the presence of lymphoplasmacytic inflammatory infiltrate and density, the presence of neutrophils as a marker of inflammatory activity, the presence of lymphoid follicles, the degree of glandular atrophy and the intestinal metaplasia. The other slide was stained with a Giemsa stain for microscopic detection of $\mathrm{H}$. pylori bacilli and the also the density of bacilli along the inner surface of mucosal epithelium.

Histopathology was assessed using Updated Sydney classification. Sydney System had different grade variables; H. Pylori density, activity, chronic inflammation, and atrophy and each graded into none, mild, moderate or severe [20]. Definition and grading guidelines for each of the histological features according to the Sydney classification are shown in Table 1 [21].

Patients were divided according to the results histopathology into two groups, those with positive histopathology 
Table 1 Definition and grading guidelines for each of the histological features to be graded according to the Sydney classification [21]

\begin{tabular}{|c|c|c|}
\hline Feature & Definition & Grading guidelines \\
\hline H. pylori & Density of helicobacter like organisms overlying epithelium & $\begin{array}{l}\text { None: no curved bacilli } \\
\text { Mild: scattered organisms } \\
\text { covering }<1 / 3 \text { of surface } \\
\text { Moderate: intermediate } \\
\text { numbers } \\
\text { Severe: large clusters or a } \\
\text { continuous layer over }> \\
2 / 3 \text { of the surface }\end{array}$ \\
\hline Activity & Neutrophil polymorph infiltration of the lamina propria, pits or surface epithelium & $\begin{array}{l}\text { None: polymorphs difficult } \\
\text { to find } \\
\text { Mild: }<1 / 3 \text { of pit and surface } \\
\text { infiltrated } \\
\text { Moderate: } 1 / 2 \text { to } 2 / 3 \text { of pit } \\
\text { and surface infiltrated } \\
\text { Severe: }>2 / 3 \text { of pit and } \\
\text { surface infiltrated }\end{array}$ \\
\hline Chronic inflammation & Increase in lymphocytes and plasma cells in the lamina propria & $\begin{array}{l}\text { None: lymphocytes and plasma } \\
\text { cells are present normal in } \\
\text { numbers } \\
\text { Mild: mild increase in density } \\
\text { Moderate: moderate increase in } \\
\text { density } \\
\text { Severe: severe increase in density }\end{array}$ \\
\hline Atrophy & Loss of specialized glands from either antrum or body & $\begin{array}{l}\text { None: absent } \\
\text { Mild: mild loss } \\
\text { Moderate: moderate loss } \\
\text { Severe: severe loss }\end{array}$ \\
\hline
\end{tabular}

for $\mathrm{H}$. pylori (H. pylori-positive patients) and those with negative histopathology for $H$. pylori $(H$. pylori-negative patients).

\section{Statistical analysis}

Data entry and data analysis were done using SPSS (Statistical Package for Social Science) version 20. Qualitative variables were presented as numbers and percentages. Normally distributed continuous variables were presented as the mean \pm standard deviation and compared using the $t$-test. Non-normally distributed continuous variables were expressed as the median and compared using the Mann-Whitney $U$ test. To assess the associations between categorical variables, the chi-squared $\left(x^{2}\right)$ test was used while Fisher exact test was used when more than $25 \%$ of the cells had expected counts less than 5. Spearman correlations were done to measure the correlation between ordinal and continuous variables. $P$ value was regarded as statistically significant when $P<$ 0.05 .

\section{Results}

The demographic characteristics of studied cases according to the $\mathrm{H}$. pylori status are presented in Table 2. According to histopathology of the taken biopsies, $56.2 \%$ of the studied cases (18 patients) proved to be $\mathrm{H}$. pyloripositive and $43.8 \%$ (14 patients) were negative. Both patient groups were comparable as regards sex and residence with insignificant differences $(P=0.618$ and 0.669 respectively). The mean age was significantly higher in $\mathrm{H}$. pyloripositive group (11.56 years) than in $\mathrm{H}$. pylori-negative group (8.43 years) with $P=0.029$ (Fig. 1).

Regarding $\mathrm{CBC}$ and coagulation profile, it was found that the hemoglobin level was significantly lower among cases than controls $(11.38 \pm 1.31$ versus $12.33 \pm 0.59$ with $P=0.001)$. Prothrombin time, prothrombin concentration, and activated partial thromboplastin time were comparable among cases and controls with no significant difference between them $(12.38 \pm 1.07$ versus $12.07 \pm 0.56,95.78 \pm 12.53$ versus $94 \pm 5.87,29.84 \pm$ 3.48 versus $28.61 \pm 2.3$ with $P=0.129,0.573$, and 0.186 respectively).

Regarding the diagnostic accuracy of the rapid urease test in the diagnosis of $\mathrm{H}$. pylori, it was found that the rapid urease test had a sensitivity of $88.9 \%$, a specificity of $92.9 \%$, a positive predictive value of $94.1 \%$, a negative predictive value of $86.7 \%$, and an accuracy of $90.6 \%$ (Table 3, Fig. 2 ).

As regards the gross upper endoscopic findings among $\mathrm{H}$. pylori-positive and negative cases, the antral affection and nodularity were significantly higher among $\mathrm{H}$. pylori-positive cases than $H$. pylori-negative cases (11 versus 2 with $P=0.012$ ) (Fig. 3 ).

Regarding the updated Sydney scoring system of gastritis in $\mathrm{H}$. pylori-positive and negative cases, there was no significant difference between the patient groups in 
Table 2 Demographic data of studied cases according to the result of $\mathrm{H}$. pylori status

\begin{tabular}{|c|c|c|c|c|c|c|}
\hline \multirow[t]{2}{*}{ Demographic } & & \multicolumn{2}{|c|}{ H. pylori-positive cases } & \multicolumn{2}{|c|}{ H. pylori-negative cases } & \multirow{2}{*}{$\begin{array}{l}P \\
\text { value }\end{array}$} \\
\hline & & $N$ & Percent & $\bar{N}$ & Percent & \\
\hline & Total & 18 & 56.2 & 14 & 43.8 & \\
\hline \multirow[t]{2}{*}{ Sex } & Male & 8 & 61.5 & 5 & 38.5 & 0.618 \\
\hline & Female & 10 & 52.6 & 9 & 47.4 & \\
\hline \multirow[t]{2}{*}{ Residence } & Rural & 15 & 60 & 10 & 40 & 0.669 \\
\hline & Urban & 3 & 42.9 & 4 & 57.1 & \\
\hline \multirow[t]{2}{*}{ Age } & & \multicolumn{2}{|c|}{ Mean \pm SD } & \multicolumn{2}{|c|}{ Mean \pm SD } & $0.029^{*}$ \\
\hline & & \multicolumn{2}{|c|}{$11.56 \pm 3.62$} & \multicolumn{2}{|c|}{$8.43 \pm 3.94$} & \\
\hline
\end{tabular}

"Statistically significant

the inflammatory activity and mucosal atrophy. The density of lymphoplasmacytic infiltrates and lymphoid follicles were more prevalent among $\mathrm{H}$. pylori-positive cases than $\mathrm{H}$. pylori-negative cases with $P$ values of 0.026 and 0.012 respectively. Regarding $\mathrm{H}$. pylori density, $38.8 \%$ of the positive cases had mild density, $27.7 \%$ had moderate density and $33.3 \%$ had severe density of $\mathrm{H}$. pylori. Definition and grading guidelines for each of the histological features were graded according to the Sydney classification $[20,21]$ (Table 4, Figs. 4, 5, and 6).

The comparison of the serum trace element level among $\mathrm{H}$. pylori-positive cases, $\mathrm{H}$. pylori-negative cases and the control group are presented in Table 5 and Fig. 7. Regarding the serum zinc levels, the mean levels were significantly lower in $\mathrm{H}$. pylori-positive cases than the control group $(84.2 \pm 13.85$ versus $94.6 \pm 6.52$ with $P=0.009$ ) and lower than $\mathrm{H}$. pylorinegative cases but not statistically significant (84.2 \pm 13.85 versus $92.2 \pm 8.53$ with $P=0.054$ ). As regards the serum selenium levels, it was slightly higher in $\mathrm{H}$. pylori-positive patients than in $\mathrm{H}$. pylori-negative patients and controls with no significant differences between $\mathrm{H}$. pylori-positive $(118.2 \pm 11.13 \mathrm{ng} / \mathrm{ml}, P=$ $0.096)$ and either the negative cases $(112.1 \pm 8.69 \mathrm{ng} /$ $\mathrm{ml}, P=0.243)$ or the control group $(113.1 \pm 13.76$ $\mathrm{ng} / \mathrm{ml}, P=0.81)$. Concerning the serum vitamin $C$ levels, the mean serum levels were significantly lower in $\mathrm{H}$. pylori-positive cases than in the negative cases and the control group $(220.7 \pm 46.16$ versus $305.1 \pm$ 28.83 and $313.1 \pm 31.43$ with $P<0.0001)$. Regarding

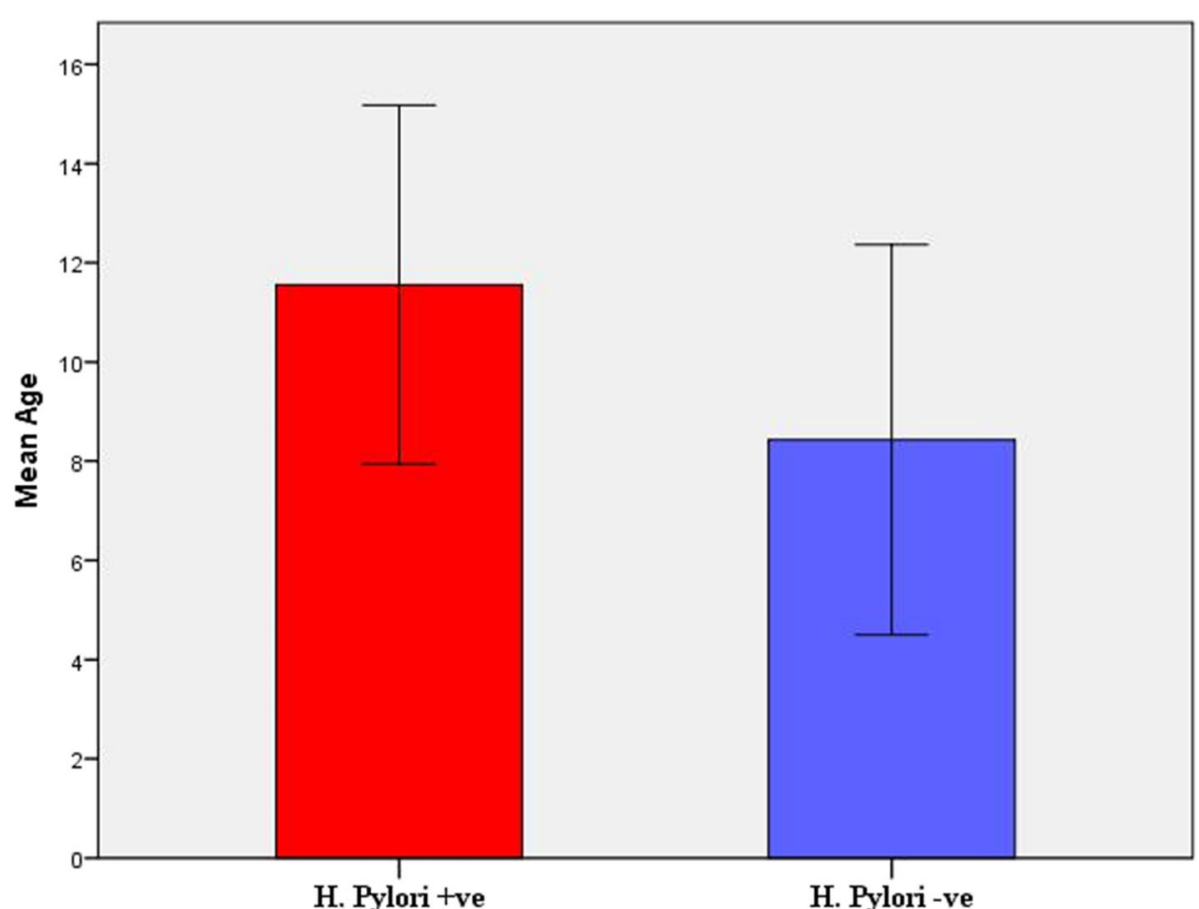

Fig. 1 Age distribution among $\mathrm{H}$. pylori-positive and negative cases 
Table 3 Performance characteristics of rapid urease test in the diagnosis of $\mathrm{H}$. pylori

\begin{tabular}{|c|c|c|c|}
\hline & & \multicolumn{2}{|l|}{ Biopsy } \\
\hline & & H. pylori-positive cases & H. pylori-negative cases \\
\hline \multirow[t]{2}{*}{ Rapid urease test } & Positi ve & 16 & 1 \\
\hline & Negati ve & 2 & 13 \\
\hline \multirow{5}{*}{\multicolumn{2}{|c|}{ Performance characteristics of rapid urease test }} & Sensitivity & $88.9 \%$ \\
\hline & & Specificity & $92.9 \%$ \\
\hline & & Positive predictive value & $94.1 \%$ \\
\hline & & Negative predictive value & $86.7 \%$ \\
\hline & & Accuracy & $90.6 \%$ \\
\hline
\end{tabular}

the serum vitamin $B_{12}$ levels, the mean serum levels were significantly lower in $\mathrm{H}$. pylori-positive cases than in the negative cases and the control group $(167.8 \pm 76.98$ versus $290.1 \pm 69.92$ and $326.1 \pm$ 38.67 with $P<0.0001)$.

Correlation between the serum levels of trace elements and the degree of severity of histopathological changes in the gastric mucosal biopsy are presented in Table 6, Figs. 8, 9, and 10. Regarding the serum zinc levels, there was a significant negative correlation with the severity of inflammatory infiltrate, mucosal atrophy, and $\mathrm{H}$. pylori density $(r=-0.4,-0.62,-0.42$ and $P=0.023,0.0001$, 0.017 respectively). Regarding the serum selenium levels, there was a significant positive correlation between selenium level and the $\mathrm{H}$. pylori density $(r=0.37$ and $P=$ 0.039). Regarding the serum vitamin $C$ levels, there was a significant negative correlation with the severity of inflammatory infiltrate, lymphoid follicles, mucosal atrophy, and $\mathrm{H}$. pylori density $(r=-0.64,-0.44,-0.54,-0.83$ and $P=0.0001,0.01,0.001,0.0001$ respectively). Regarding the serum vitamin $B_{12}$ levels, there was a significant negative correlation with the severity of inflammatory infiltrate, mucosal atrophy, and $\mathrm{H}$. pylori density $(r=$
$-0.44,-0.41, \quad-0.74$ and $P=0.012,0.02, \quad 0.0001$ respectively).

\section{Discussion}

Trace minerals and vitamins are essential for life. They act as essential cofactors of enzymes and as organizers of the molecular structures of the cell. Deficiencies of micronutrients influence immune homeostasis and thus affect infection-related morbidity and mortality [6]. H. pylori can change the secretion and acidification functions of the stomach, because it penetrates especially into the stomach. This situation can affect digestion and absorption of some components of the nutrients and micronutrients [15].

The present study showed that the mean age of our children was significantly higher in $\mathrm{H}$. pylori-positive group (11.56 years) than in $\mathrm{H}$. pylori-negative group (8.43 years) (Table 2 and Fig. 1). This finding is similar to that reported by Malaty et al. [22] and Jafar et al. [23] who found that there were increasing prevalence rates of $\mathrm{H}$. pylori infection with increasing age in all age groups.
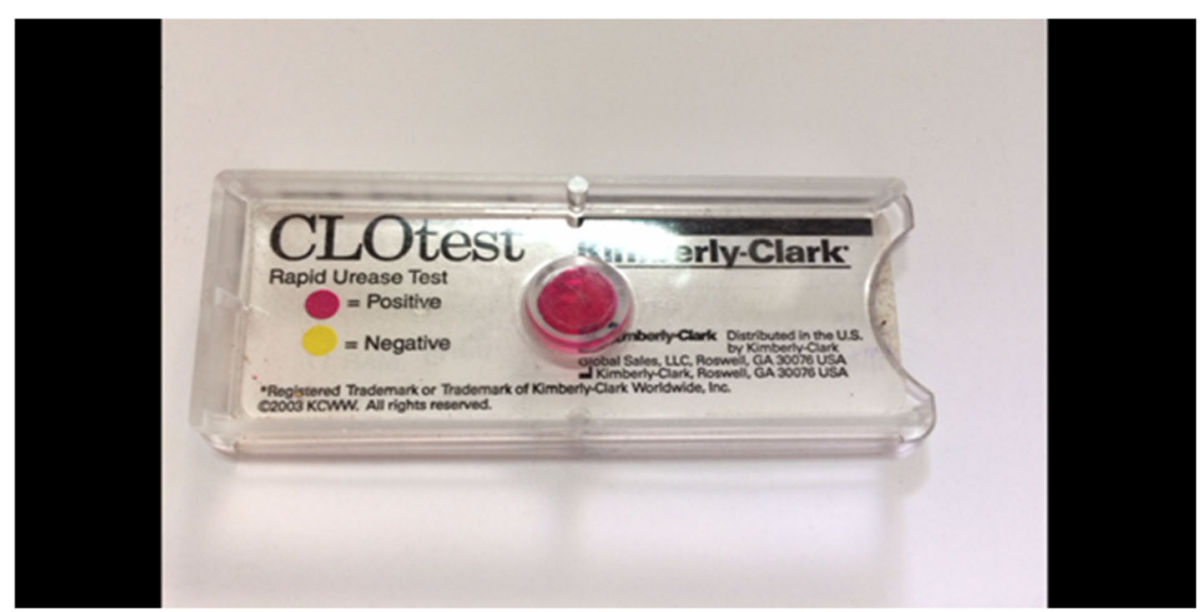

Fig. 2 Positive rapid urease test 


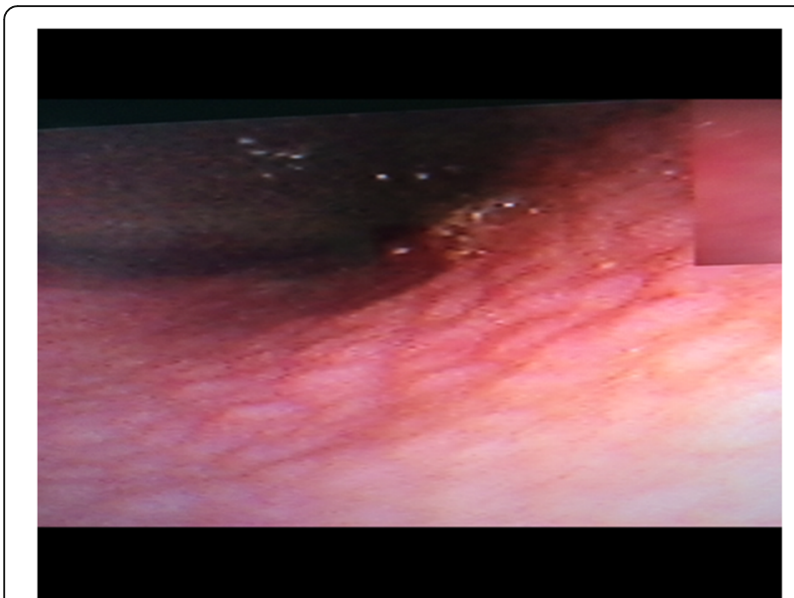

Fig. 3 Endoscopic view of antral nodularity

Regarding the accuracy of rapid urease test in the diagnosis of $\mathrm{H}$. pylori infection, the present study found that rapid urease test had a sensitivity of $88.9 \%$ and a specificity of $92.9 \%$ (Table 3). This finding is nearly similar to that reported by previous studies who found that the sensitivity of various rapid urease tests as primary diagnostic tests is high and has been reported to vary between approximately $80 \%$ and $100 \%$ and specificity between $97 \%$ and $99 \%[24,25]$. The rapid urease test is a test for the presence of the urease enzyme. The actual results will depend on the gastric disease and the likelihood of atrophic changes or exogenous factors that reduce the bacterial load (such as the use of antibiotics, bismuth-containing compounds, or proton pump inhibitors) and thus produce falsenegative results [26]. The two most common reasons for false-negative results are the recent use of proton pump inhibitors and the presence of intestinal metaplasia. $\mathrm{H}_{2}$-receptor antagonists do not reduce the bacterial density and can be used up to

Table 4 Updated Sydney scoring system of gastritis among $\mathrm{H}$. pylori-positive and negative cases

\begin{tabular}{|c|c|c|c|c|c|c|}
\hline \multirow[t]{2}{*}{$\begin{array}{l}\text { Histopathologic } \\
\text { parameter }\end{array}$} & \multirow[t]{2}{*}{ Grade } & \multicolumn{2}{|c|}{$\begin{array}{l}\text { H. pylori- } \\
\text { positive } \\
\text { cases } \\
(N=18)\end{array}$} & \multicolumn{2}{|c|}{$\begin{array}{l}\text { H. pylori- } \\
\text { negative } \\
\text { cases } \\
(N=14)\end{array}$} & \multirow[t]{2}{*}{$P$} \\
\hline & & $N$ & Percent & $N$ & Percent & \\
\hline Inflammatory activity & Mild & 1 & $5.6 \%$ & 0 & - & 0.378 \\
\hline \multirow[t]{2}{*}{ Inflammatory infiltrate } & Mild & 9 & $50 \%$ & 11 & $78.2 \%$ & $0.026^{*}$ \\
\hline & Moderate & 9 & $50 \%$ & 2 & $14.3 \%$ & \\
\hline Lymphoid follicles & Present & 11 & $61.1 \%$ & 2 & $14.3 \%$ & $0.012^{*}$ \\
\hline \multirow[t]{2}{*}{ Mucosal atrophy } & Mild & 4 & $22.2 \%$ & 0 & - & 0.103 \\
\hline & Moderate & 2 & $11.1 \%$ & 1 & $7.1 \%$ & \\
\hline
\end{tabular}

"Statistically significant

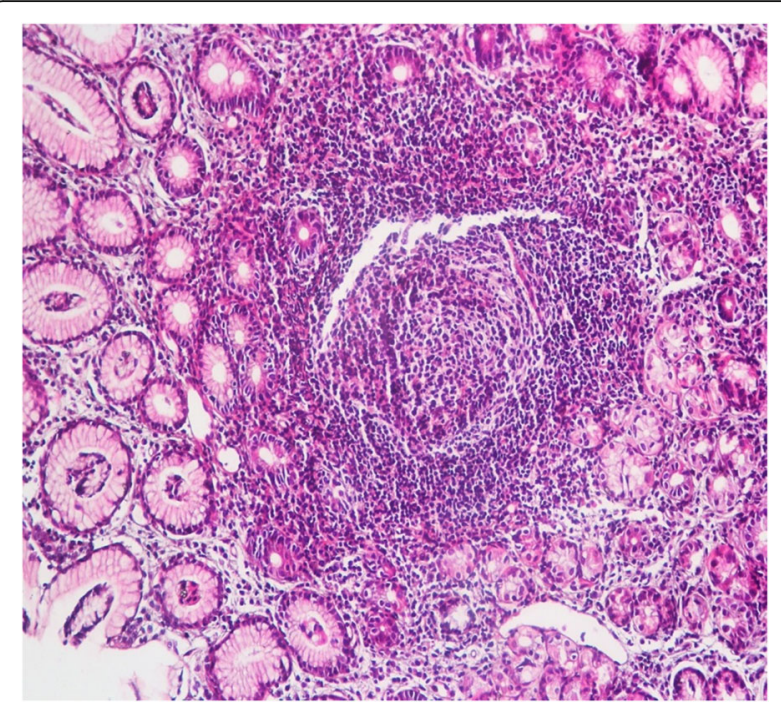

Fig. 4 Section from the gastric mucosal endoscopic biopsy which shows chronic gastritis with the presence of reactive lymphoid follicles (H\&E, 200x)

the day of the test [27]. Also, false-negative results can occur if the distribution within the stomach is patchy or if organism loads are low and the presence of atrophic gastritis with or without intestinal dysplasia [28]. False-positives are rare and when present may be due to the presence of other ureasecontaining organisms such as Proteus mirabilis, Citrobacter freundii, Klebsiella pneumonia, Enterobacter cloacae, and Staphylococcus aureus [29].

Concerning the gross endoscopic picture of studied cases, the present study found that antral affection and

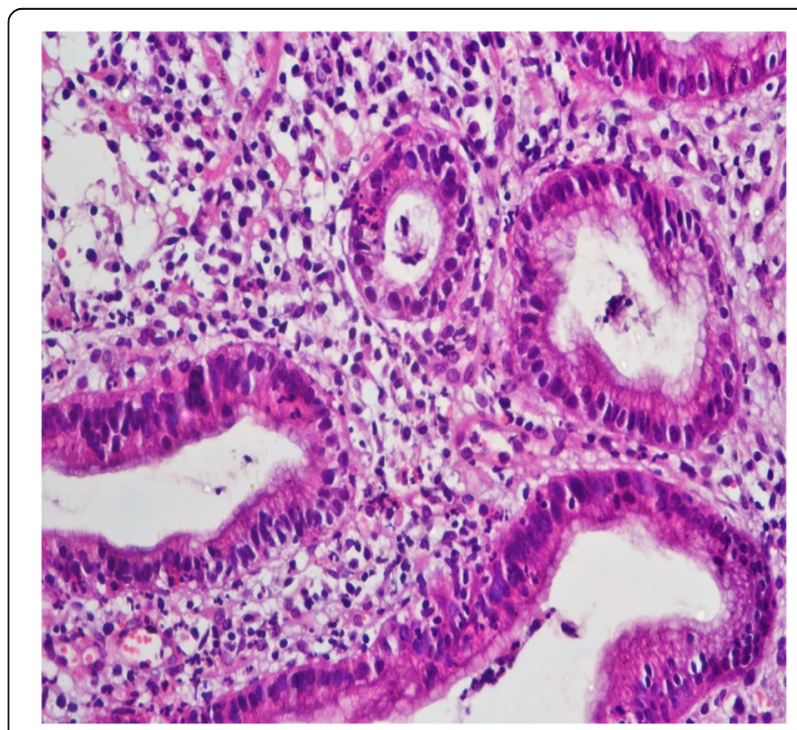

Fig. 5 Section from the gastric mucosal endoscopic biopsy which shows chronic gastritis with activity appreciated by the presence of neutrophils attacking the gastric glands (H\&E, 400X) 


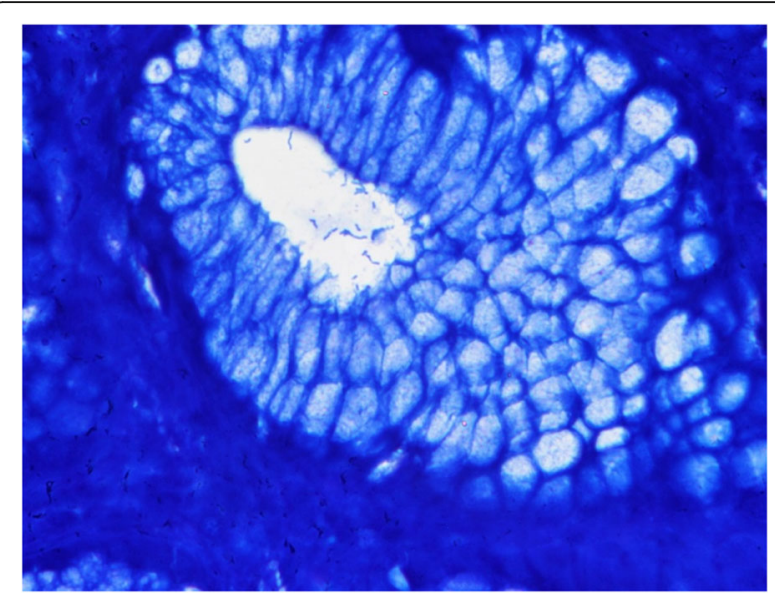

Fig. 6 Section from the gastric mucosal endoscopic biopsy which shows numerous Helicobacter pylori curved bacilli on the inner surface of gastric glands (Giemsa stain, oil immersion)

nodularity were significantly higher among $\mathrm{H}$. pyloripositive cases than $H$. pylori-negative cases (11 versus 2 with $P=0.012$ ) (Fig. 3 ). In agreement with this finding, Bahú et al. [30] concluded that endoscopic findings of antral nodularity in children suggest the presence of $\mathrm{H}$. pylori infection and follicular gastritis and may identify cases of severe gastritis and marked bacterial colonization. Also, Tomasević et al. [31] reported that $\mathrm{H}$. pylori infection is known to be the most common cause of chronic gastritis having some endoscopic and pathologic characteristics as determined by the Sydney System for Gastritis Classification. They found that there is an association of $\mathrm{H}$. pylori infection and of lymphoid follicles with the nodular gastric mucosa. Similarly, Romero-Flores et al. [32] found that there was a strong correlation between nodular gastritis and $\mathrm{H}$. pylori, but only after rigorous evaluation.

H. pylori infection is significantly associated with lymphoid follicle formation on histopathological examination. Lymphoid follicles and aggregates have been detected in 32.9-85\% of chronic gastritis patients on histological examination of biopsy specimens, and appear more common in the antral mucosa than in the corpus mucosa [33]. The severity of gastritis is also correlated with the presence of lymphoid follicles and aggregates. A close relationship exists between lymphoid follicles and $H$. pyloriassociated gastritis. The endoscopic features of such lymphoid follicles have been reported as nodular gastritis. Nodular gastritis (antral nodularity) is a unique type of chronic gastritis caused by $\mathrm{H}$. pylori infection [34]. Chen et al. [35] concluded that the prevalence and density of lymphoid follicles and aggregates in gastric antral mucosal biopsies correlated closely with $H$. pylori infection. Similarly, Hayashi et al. [36] concluded that the endoscopic finding of nodules could be observed at any site of the gastric mucosa in $H$. pylori-associated gastritis, and represented histological lymphoid follicles. Moreover, these follicles are thought to represent the pathophysiologic substrate for mucosa-associated lymphoid tissue-lymphomas [37].

Regarding the serum zinc levels, the present study found that the mean levels were significantly lower in $\mathrm{H}$. pylori-positive cases than in the control group and lower than $\mathrm{H}$. pylori-negative cases but not statistically significant (Table 5). Brown et al. [38] stated that a protein that strongly binds to zinc has been identified on the membrane and in the cytosol of $\mathrm{H}$. pylori. Because zinc is absorbed mainly in the small intestine, by binding dietary zinc in the stomach, $\mathrm{H}$. pylori may possibly contribute to serum zinc deficiency. Wu et al. [39] reported that the serum zinc level was lower in $H$. pylori-infected patients compared with $H$. pylori-negative cases. However, the difference was not statistically significant.

The present study also reported that the serum zinc concentration had a significant negative correlation with the severity of inflammatory infiltrate, mucosal atrophy, and $\mathrm{H}$. pylori density with insignificant negative correlation with the severity of inflammatory activity (Table 6). This is in agreement with Sempertegui et al. [40] who reported that the more

Table 5 Comparison of serum trace element level among $\mathrm{H}$. pylori-positive cases, $\mathrm{H}$. pylori-negative cases, and the control group

\begin{tabular}{|c|c|c|c|c|c|c|}
\hline & H. pylori-positive $(N=18)$ & H. pylori-negative $(N=14)$ & Controls $(N=18)$ & $P_{1}$ & $P_{2}$ & $P_{3}$ \\
\hline Micronutrient & Mean \pm SD & Mean \pm SD & Mean \pm SD & & & \\
\hline Zinc $(\mu \mathrm{g} / \mathrm{dl})$ & $84.2 \pm 13.85$ & $92.2 \pm 8.53$ & $94.6 \pm 6.52$ & 0.054 & $0.009^{*}$ & 0.403 \\
\hline Selenium (ng/ml) & $118.2 \pm 11.13$ & $112.1 \pm 8.69$ & $113.1 \pm 13.76$ & 0.096 & 0.243 & 0.81 \\
\hline Vit C (ng/l) & $220.7 \pm 46.16$ & $305.1 \pm 28.83$ & $313.1 \pm 31.43$ & $0.0001^{*}$ & $0.0001^{*}$ & 0.458 \\
\hline Vit $B_{12}(n g / l)$ & $167.8 \pm 76.980$ & $290.1 \pm 69.92$ & $326.1 \pm 38.67$ & $0.0001^{*}$ & $0.0001^{*}$ & 0.1 \\
\hline
\end{tabular}

$\mathrm{P}_{1}: \mathrm{H}$. pylori-positive versus $\mathrm{H}$. pylori-negative

$\mathrm{P}_{2}$ : H. pylori-positive versus controls

$\mathrm{P}_{3}$ : H. pylori-negative versus controls

*Statistically significant 


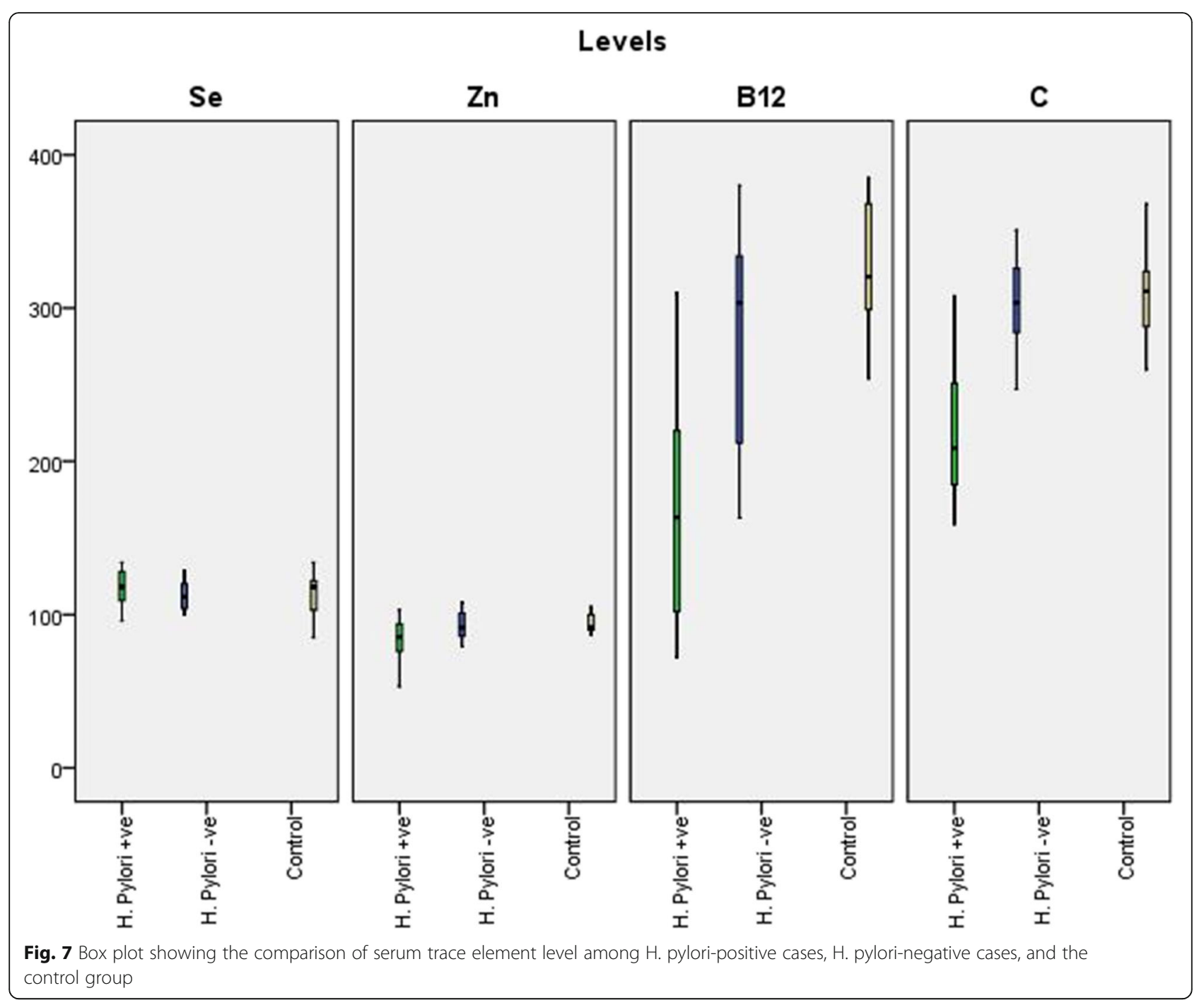

Table 6 Correlation between the serum levels of trace elements and the degree of severity of histopathological changes in gastric mucosal biopsy

\begin{tabular}{llllll}
\hline Histopathological parameters & & Zn & Selenium & Vit. C & Vit. $B_{12}$ \\
\hline Inflammatory activity & $\mathrm{R}$ & -0.22 & 0.29 & -0.3 & -0.28 \\
& $\mathrm{P}$ & 0.22 & 0.11 & 0.09 & 0.12 \\
Inflammatory infiltrate & $\mathrm{R}$ & -0.4 & 0.15 & -0.64 & -0.44 \\
& $\mathrm{P}$ & $0.023^{\mathrm{a}}$ & 0.42 & $0.0001^{\mathrm{a}}$ & $0.012^{\mathrm{a}}$ \\
Lymphoid follicles & $\mathrm{R}$ & -0.08 & 0.12 & -0.44 & -0.22 \\
& $\mathrm{P}$ & 0.65 & 0.51 & $0.01^{\mathrm{a}}$ & 0.23 \\
Mucosal atrophy & $\mathrm{R}$ & -0.62 & 0.007 & -0.54 & -0.41 \\
& $\mathrm{P}$ & $0.0001^{\mathrm{a}}$ & 0.97 & $0.001^{\mathrm{a}}$ & $0.02^{\mathrm{a}}$ \\
H. pylori density & $\mathrm{R}$ & -0.42 & 0.37 & -0.83 & -0.74 \\
& $\mathrm{P}$ & $0.017^{\mathrm{a}}$ & $0.039^{\mathrm{a}}$ & $0.0001^{\mathrm{a}}$ & $0.0001^{\mathrm{a}}$ \\
\hline
\end{tabular}

${ }^{\text {aStatistically significant }}$ severe the $\mathrm{H}$. pylori infection, the lower concentration of zinc in gastric mucosa.

Regarding the serum selenium levels, it was slightly higher in $\mathrm{H}$. pylori-positive patients than in $\mathrm{H}$. pylorinegative patients and controls with no significant differences between $\mathrm{H}$. pylori-positive cases and either the negative cases or the control group (Table 5). Wu et al. [39] have shown that serum selenium level had no significant difference between $\mathrm{H}$. pylori-positive and $\mathrm{H}$. pylori-negative groups. However, the serum selenium levels decrease after $H$. pylori eradication therapy.

In this study, there was a significant positive correlation between serum selenium level and the $\mathrm{H}$. pylori density (Table 6). Üstündag et al. [14] reported that plasma selenium levels were similar between $H$. pylori-positive gastritis and healthy controls, but in the gastric tissue selenium levels were significantly higher in $\mathrm{H}$. pylori-positive gastritis. There was a 


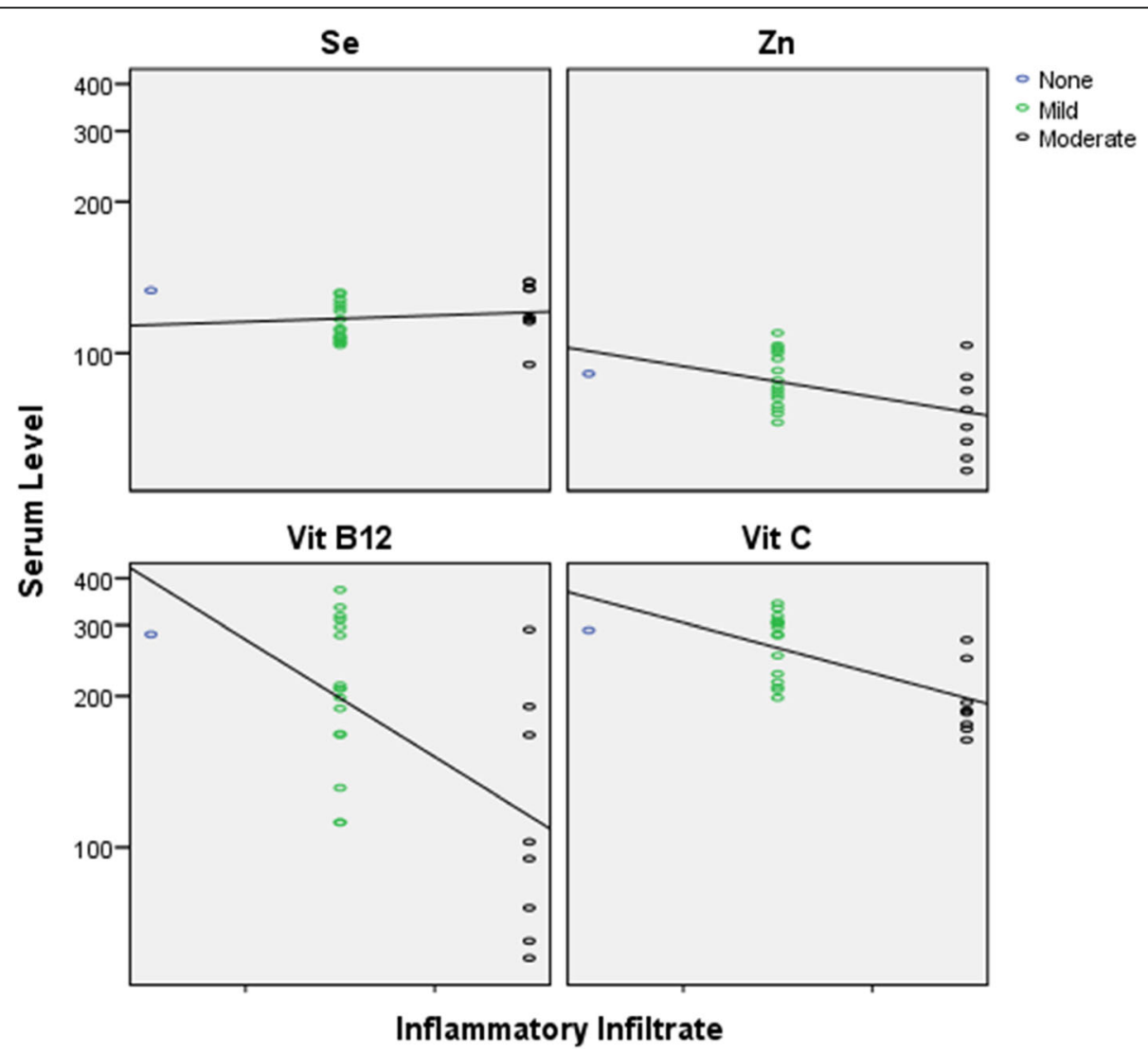

Fig. 8 Scatter plot of the correlation between serum levels of trace elements and the degree of inflammatory cell infiltrate in the gastric mucosal biopsy

statistically significant decrease in mucosal selenium levels in patients after successful $\mathrm{H}$. pylori eradication therapy. The increased selenium levels may be explained on the basis of elevated reactive oxygen species in association with $\mathrm{H}$. pylori infection.

In the present study, the mean serum vitamin $C$ levels were significantly lower in $\mathrm{H}$. pylori-positive cases than in the negative cases and the control group (Table 5). In line with our results, Waring et al. [41] reported that vitamin C plasma concentration was $20 \%$ lower in $\mathrm{H}$. pylori-infected subjects than in negative controls, even after correction for confounding factors, such as dietary habits.

Also, regarding the serum vitamin $\mathrm{C}$ levels, there was a significant negative correlation with the severity of inflammatory infiltrate, lymphoid follicles, mucosal atrophy, and $H$. pylori density (Table 6). In line with these results, Park et al. [42] found that vitamin $\mathrm{C}$ levels in whole blood, plasma, and gastric juice were closely related to the severity of $\mathrm{H}$. pylori infection and the histological changes in the stomach. These authors reported that vitamin $\mathrm{C}$ can have a role in the initiation and progression of $\mathrm{H}$. pylori infection. They also reported that vitamin $\mathrm{C}$ levels in whole blood, plasma, and gastric juice exhibited a significant negative correlation with the histologic density of $\mathrm{H}$. pylori, the degree of active and chronic gastritis, and the severity of $\mathrm{H}$. pylori infection (based on urease positivity and histologic density of $\mathrm{H}$. pylori). There are several explanations for the reduction of ascorbic acid in the gastric juice of $\mathrm{H}$. pylori-infected subjects. First of all, ascorbic acid may be consumed acting as a scavenger against reactive oxygen species, produced by gastric inflammation.

Regarding the serum vitamin $B_{12}$ levels, the present study found that the mean levels were significantly lower in $\mathrm{H}$. pylori-positive cases than in the negative cases and the control group (Table 5). In addition, it was found that serum vitamin $B_{12}$ levels showed a significant negative correlation with the severity of inflammatory infiltrate, mucosal atrophy, and H. pylori density (Table 6). Similar to these results, Akcam et al. [43] found a statistically significant relation between $\mathrm{H}$. pylori infection and serum vitamin $B_{12}$ levels that were independent of 


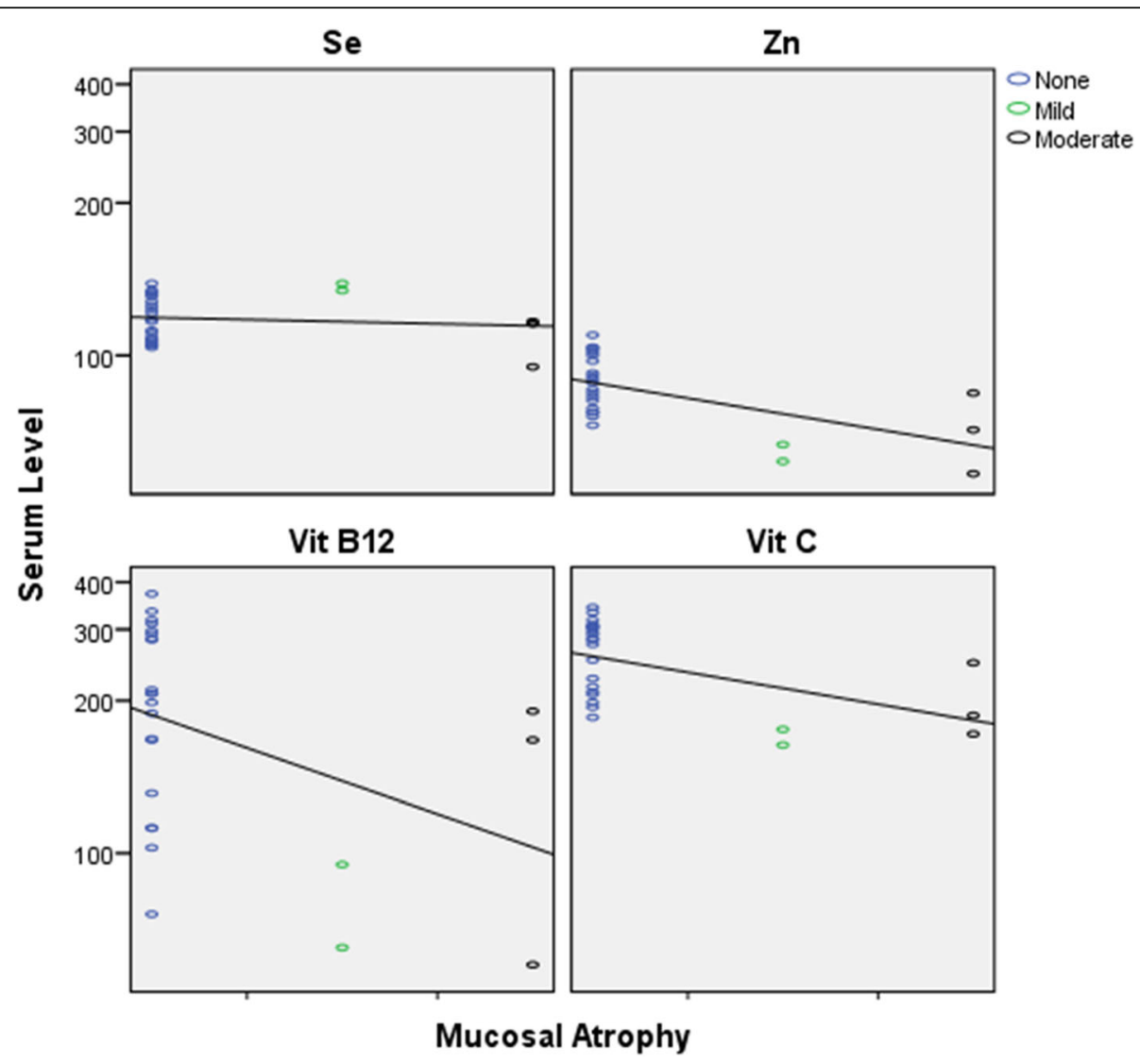

Fig. 9 Scatter plot of the correlation between serum levels of trace elements and the degree of mucosal atrophy in the gastric mucosal biopsy

gastric atrophy and suggested that $\mathrm{H}$. pylori infection had a negative effect on serum vitamin $\mathrm{B}_{12}$ levels in children. Similarly, Ravi et al. [44] reported a significant relationship between the $\mathrm{B}_{12}$ levels and the $\mathrm{H}$. pylori status, where $58 \%$ of the $\mathrm{H}$. pylori-positive patients had vitamin $\mathrm{B}_{12}$ values below $100 \mathrm{pg} / \mathrm{mL}$ in contrast to $38 \%$ of $\mathrm{H}$. pylorinegative cases. Hence, the $H$. pylori-positive patients group had a significantly lower vitamin $B_{12}$ value compared to the $H$. pylori-negative patients group.

Annibale et al. [45] demonstrated that almost twothirds of pernicious anemia patients had evidence of $H$. pylori but only those with an active $H$. pylori infection had distinct functional and histological features. These findings support the hypothesis that $\mathrm{H}$. pylori infection could play a triggering role in a subgroup of patient with pernicious anemia and suggest the possibility that $\mathrm{H}$. pylori is involved in the early stages of pernicious anemia that lead to severe corpus atrophy. The later progress of gastritis seems to be dependent on factors other than $\mathrm{H}$. pylori, most likely "autoimmune" mechanisms.
Serin et al. [46] demonstrated that the histopathological scores for $\mathrm{H}$. pylori density, inflammation, and neutrophil activity were all inversely correlated with serum vitamin $B_{12}$ level and the linear regression analysis revealed that only $\mathrm{H}$. pylori density was significantly correlated with serum $\mathrm{B}_{12}$ level. After treatment, the serum vitamin $B_{12}$ levels were significantly increased, and the inflammation and neutrophil activity scores in the antrum and corpus were significantly decreased, regardless of eradication status. With patients categorized according to eradication status, the elevation in serum vitamin $B_{12}$ level was more pronounced in the group in which the organism had been completely eradicated than in those with persistent infection.

Several limitations of the present study should be discussed. First, the relatively small number of patients. Furthermore, we measured only plasma levels of the trace elements and vitamins with lack of measurement of gastric mucosal trace elements. Third, the lack of measurement of the plasma levels of the trace elements and vitamins after eradication therapy. 


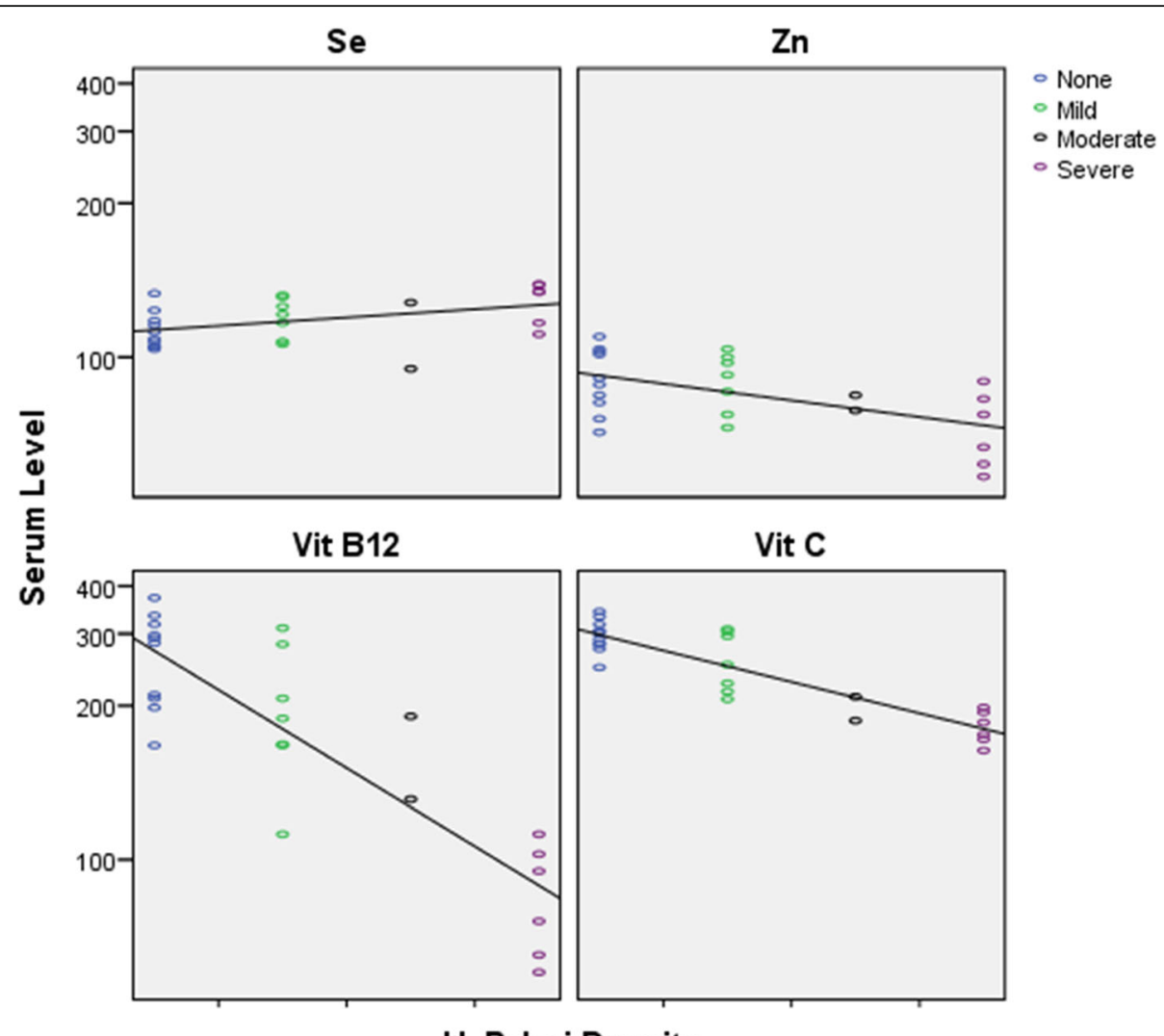

H. Pylori Density

Fig. 10 Scatter plot of the correlation between serum levels of trace elements and the density of H. pylori in the gastric mucosal biopsy

\section{Conclusion}

The present study concluded that $\mathrm{H}$. pylori infection was more common among older children. The rapid urease test had a comparable accuracy to histopathological examination in the diagnosis of $\mathrm{H}$. pylori infection. Antral nodularity in children suggests the presence of $\mathrm{H}$. pylori infection and may identify cases of severe gastritis and marked bacterial colonization, histologically, prominent lymphoid follicles are seen. H. pylori infection in children has a significant negative effect on the blood levels of zinc, vitamin $C$, and vitamin $B_{12}$. The deficiency of zinc, vitamin $C$, and vitamin $B_{12}$ had a significant negative correlation with the severity of inflammatory infiltrate, mucosal atrophy, and $\mathrm{H}$. pylori density.

\section{Supplementary information}

Supplementary information accompanies this paper at https://doi.org/10. 1186/s43054-020-0017-3.

Additional file 1. Anthropometric data of studied cases.

\section{Abbreviations}

aPTT: Activated partial thromboplastin time:

EGD: Esophagogastroduodenoscopy; ELISA: Enzyme-linked immunosorbent assay; Gl: Gastrointestinal; H. pylori: Helicobacter pylori; Hb\%: Hemoglobin percent; INR: International normalized ratio; $P$ value: Probability value or significance; PT: Prothrombin time; SD: Standard deviation; SPSS: Statistical Package for Social Science; WHO: World Health Organization; $X^{2}$ test: Chisquared test

\section{Acknowledgements \\ None}

\section{Authors' contributions}

AME designed the study, evaluated the patients, collected, analyzed, and interpreted the data, and wrote the manuscript. FHA, NHA, and HSF contributed to the conception and design of the study, literature search, data analysis, and manuscript review. MAH contributed to micronutrient assay and data analysis. MFS contributed to histopathologic assessment of gastric mucosal biopsies and data analysis. All authors read and approved the final manuscript.

\section{Funding}

Faculty of Medicine, Assiut University. The fund used to order the kits used for micronutrient assay.

\section{Availability of data and materials}

All data generated or analyzed during this study are included in this published article and its Additional file 1.

\section{Ethics approval and consent to participate}

The study was approved by the ethics committee of the Faculty of Medicine, Assiut University (IRB no: 17200360). Written informed consents were taken from parents with explanation of benefits of the study; risks expected and suggested treatment for each case.

Consent for publication

Not applicable 


\section{Competing interests}

The authors declare that they have no competing interests.

\section{Author details}

'Department of Pediatrics, Faculty of Medicine, Assiut University, Assiut 71515, Egypt. ${ }^{2}$ Department of Medical Biochemistry, Faculty of Medicine, Assiut University, Assiut, Egypt. ${ }^{3}$ Department of Pathology, Faculty of Medicine, Assiut University, Assiut, Egypt.

Received: 4 October 2019 Accepted: 31 December 2019 Published online: 03 February 2020

\section{References}

1. Pajares JM, Gisbert JP (2006) Helicobacter pylori: its discovery and relevance for medicine. Rev Esp Enferm Dig 98(10):770-785

2. Malfertheiner P, Megraud F, O'Morain CA et al (2012) Management of Helicobacter pylori infection-the Maastricht IV/ Florence Consensus Report. Gut 61(5):646-664

3. Hunt R, Xiao S, Megraud F, Leon-Baura R, Bazzoli F, van der Merwe S et al (2011) World Gastroenterology Organisation Global Guideline-Helicobacter pylori in developing countries. J Cin Gastroenterol 45(5):383-388

4. Salgueiro J, Zubillaga M, Goldman C et al (2004) Review article: Is there a link between micronutrient malnutrition and Helicobacter pylori infection? Aliment Pharmacol Ther 20(10):1029-1034

5. Dale A, Thomas JE, Darboe MK, Coward WA, Harding M, Weaver LT (1998) Helicobacter pylori infection, gastric acid secretion, and infant growth. J Pediatr Gastroenterol Nutr 26(4):393-397

6. Yakoob J, Jafri W, Abid S (2003) Helicobacter pylori infection and micronutrient deficiencies. World J Gastroenterol 9:2137-2139

7. Kurekci AE, Atay AA, Sarici SU, Yesilkaya E, Senses Z, Okutan V, Ozcan O (2005) Is there a relationship between childhood Helicobacter pylori infection and iron deficiency anemia? J Trop Pediatr 51(3):166-169

8. Desai HG, Gupte PA (2007) Helicobacter pylori link to pernicious anaemia. J Assoc Physicians India 55:857-859

9. Patten JP (2000) Neurological differential diagnosis, 2nd edn. Springer, New York, pp 234-235

10. Levine M, Padayatty SJ, Espey MG (2011) Vitamin C: a concentration function approach yields pharmacology and therapeutic discoveries. Adv. Nutr 2(2):78-88. https://doi.org/10.3945/an.110.000109

11. Padayatty SJ, Levine M (2016) Vitamin C physiology: the known and the unknown and Goldilocks. Oral Dis 22(6):463-493. https://doi.org/10.1111/odi. 12446

12. Naidu KA (2003) Vitamin C in human health and disease is still a mystery? An overview. Nutr. J 2:7. https://doi.org/10.1186/1475-2891-2-7

13. Grosso G, Bei R, Mistretta A, Marventano S, Calabrese G, Masuelli L, Giganti MG, Modesti A, Galvano F, Gazzolo D (2013) Effects of vitamin C on health: a review of evidence. Front. Biosci. (Landmark Ed). 18:1017-1029. https://doi. org/10.2741/4160

14. Üstündag Y, Boyacioglu S, Haberal A, Demirhan B, Bilezikçi B (2001) Plasma and gastric tissue selenium levels in patients with Helicobacter pylori infection. J Clin Gastroenterol 32(5):405-408

15. Akcam M (2010) Helicobacter pylori and micronutrients. Indian Pediatr 47(2): $119-126$

16. Brown KH, Peerson JM, Baker SK, Hess SY (2009) Preventive Zinc Supplementation among Infants, Preschoolers, and Older Prepubertal Children. Food Nutr Bull 30(Suppl 1):S12-S40. https://doi.org/10.1177/ $15648265090301 S 103$

17. Stanghellini V, Chan FK, Hasler WL, Malagelada JR, Suzuki H, Tack J, Talley NJ (2016) Gastroduodenal disorders. Gastroenterology 150(6):1380-1392

18. Drossman DA (2016) Functional gastrointestinal disorders: history, pathophysiology, clinical features and Rome IV. Gastroenterology 150(6): 1262-1279

19. WHO (2011) Haemoglobin concentrations for the diagnosis of anaemia and assessment of severity. Vitamin and Mineral Nutrition Information System. World Health Organization (WHO/NMH/NHD/MNM/11.1), Geneva

20. Dixon M, Genta R, Yardley J, Correa P (1994) Classification and grading of gastritis. The updated Sydney system. International workshop on the histopathology of gastritis, Huoston. Ann J Surg Pathol 20(10):1161-1181

21. Kim D-Y, Baek J-Y (1999) The comparison of histologic gastritis in patients with duodenal ulcer, chronic gastritis, gastric ulcer and gastric cancer. Yonsei Med J 40(1):14-19
22. Malaty HM, Logan ND, Graham DY, Ramchatesingh JE (2001) Helicobacter pylori Infection in Preschool and School-Aged Minority Children: Effect of Socioeconomic Indicators and Breast-Feeding Practices. CID 32(10):1387-1392

23. Jafar S, Jalil A, Soheila N, Sirous S (2013) Prevalence of Helicobacter pylori infection in children, a population-based cross-sectional study in West Iran. Iran J Pediatr 23(1):13-18

24. Calvet X, Sánchez-Delgado J, Montserrat A et al (2009) Accuracy of diagnostic tests for Helicobacter pylori: a reappraisal. Clin Infect Dis 48(10): 1385-1391

25. Redéen S, Petersson F, Törnkrantz E, Levander H, Mårdh E, Borch K (2011) Reliability of diagnostic tests for Helicobacter pylori Infection. Gastroenterol Res Pract. Vol. 2011:940650. https://doi.org/10.1155/2011/940650

26. Graham DY, Opekun AR, Hammoud F et al (2003) Studies regarding the mechanism of false negative urea breath tests with proton pump inhibitors. Am J Gastroenterol 98(5):1005-1009

27. Attumi TA, Graham DY (2011) Follow-up testing after treatment of Helicobacter pylori infections: cautions, caveats, and recommendations. Clin Gastroenterol Hepatol 9(5):373-375

28. Syrjänen K (2017) False negative and false positive results in diagnosis of Helicobacter pylori infections can be avoided by a panel of serum biomarkers (GastroPanel ${ }^{\circledR}$ ). Mathews J Gastroenterol Hepatol 1(1):007-014

29. Osaki T, Mabe K, Hanawa T et al (2008) Urease-positive bacteria in the stomach induce a false-positive reaction in a urea breath test for diagnosis of Helicobacter pylori infection. J Med Microbiol 57(7):814-819

30. Bahú SMG, Silveira RT, Maguilnick I, Ulbrich-Kulczynski J (2003) Endoscopic Nodular Gastritis: An Endoscopic Indicator of High-Grade Bacterial Colonization and Severe Gastritis in Children with Helicobacter pylori. J Pediatr Gastroenterol Nutr 36(2):217-222

31. Tomasević R, Golubović G, Kiurski M, Stanković D, Doder R, Pavlović A (2006) Association of Helicobacter pylori infection with nodular antritis and follicular gastritis. Vojnosanit Pregl 63(3):313-315

32. Romero-Flores JL, Fernandez-Rivero JA, Marroquín-Fabian E, Téllez-Ávila Fl, Sánchez-Jiménez BA, Juárez-Hernández E, Uribe M, Chávez-Tapia NC (2016) Diagnostic accuracy of nodular gastritis for $\mathrm{H}$. pylori infection. Ther Clin Risk Manag 13:9-14

33. Yakoob MY, Hussainy AS (2010) Chronic gastritis and Helicobacter pylori: A histopathological study of gastric mucosal biopsies. J Coll Physicians Surg Pak 20(11):773-775

34. Chen Q, Espey MG, Sun AY, Lee JH, Krishna MC, Shacter E et al (2007) Ascorbate in pharmacologic concentrations selectively generates ascorbate radical and hydrogen peroxide in extracellular ?uid in vivo. Proc Natl Acad Sci U.S.A 104(21):8749-8754

35. Chen XY, Liu WZ, Shi Y, Zhang DZ, Xiao SD, Tytgat GN (2002) Helicobacter pylori associated gastric diseases and lymphoid tissue hyperplasia in gastric antral mucosa. J Clin Pathol 55(2):133-137

36. Hayashi S, Imamura J, Kimura K, Saeki S, Hishima T (2015) Endoscopic features of lymphoid follicles in Helicobacter pylori-associated chronic gastritis. Dig Endoscopy 27(1):53-60

37. Nakamura S, Matsumoto T, Ye H et al (2006) Helicobacter pylori-negative gastric mucosa-associated lymphoid tissue lymphoma. A clinicopathologic and molecular study with reference to antibiotic treatment. Cancer 107(12): 2770-2778

38. Brown KH, Rivera JA, Bhutta Z, Gibson RS, King JC, Lonnerdal B, Ruel MT, Sandtrom B, Wasantwisut E, Hotz C (2004) International Zinc Nutrition Consultative Group (IZiNCG) technical document \#1. Assessment of the risk of zinc deficiency in populations and options for its control. Food Nutr Bull 25:S99-S203

39. Wu MC, Huang CY, Kuo FC et al (2014) The effect of Helicobacter pylori eradication on the levels of essential trace elements. Biomed Res Int 2014: 513725. https://doi.org/10.1155/2014/513725

40. Sempértegui F, Díaz M, Mejía R et al (2007) Low concentrations of zinc in gastric mucosa are associated with increased severity of Helicobacter pyloriinduced inflammation. Helicobacter 12(1):43-48

41. Waring AJ, Drake IM, Schorah CJ, White KL, Lynch DA, Axon AT et al (1996) Ascorbic acid and total vitamin C concentrations in plasma, gastric juice, and gastrointestinal mucosa: effects of gastritis and oral supplementation. Gut 38(2):171-176

42. Park JH, Kim SY, Kim DW, Lee WG, Rhee KH, Youn HS (2003) Correlation between Helicobacter pylori infection and vitamin C levels in whole blood, plasma, and gastric juice, and the $\mathrm{pH}$ of gastric juice in Korean children. J Pediatr Gastroenterol Nutr 37(1):53-62 
43. Akcam M, Ozdem S, Yilmaz A, Gultekin M, Artan R (2007) Serum ferritin, vitamin B (12), folate, and zinc levels in children infected with Helicobacter pylori. Dig Dis Sci 52(2):405-410

44. Ravi K, Joseph J, Thomas DM (2017) Helicobacter pylori infection and vitamin B-12 deficiency- A cross sectional study. Asian J Med Sci 8(4):16-20

45. Annibale B, Lahner E, Bordi C, Martino G, Caruana P, Grossi C et al (2000) Role of Helicobacter pylori infection in pernicious anaemia. Dig Liver Dis 32(9):756-762

46. Serin E, Gümürdülü Y, Özer B, Kayaselçuk F, Yilmaz U and Koçak R (2002) Impact of Helicobacter pylori on the development of vitamin B12 deficiency in the absence of gastric atrophy. departments of gastroenterology, pathology, and hematology, Baskent University Faculty of Medicine, Adana Teaching and Medical Research Center, Adana, Turkey. Blackwell Science Ltd, Helicobacter 7(6):337-341.

\section{Publisher's Note}

Springer Nature remains neutral with regard to jurisdictional claims in published maps and institutional affiliations.

\section{Submit your manuscript to a SpringerOpen ${ }^{\circ}$ journal and benefit from:}

- Convenient online submission

- Rigorous peer review

- Open access: articles freely available online

High visibility within the field

- Retaining the copyright to your article

Submit your next manuscript at $\boldsymbol{\nabla}$ springeropen.com 